\title{
Modified lower eyelid blepharoplasty improves aesthetic outcomes in patients with hypoplastic malar prominences
}

\author{
Muhammad Adil Abbas Khan', Kanza Aziz², Ammar Asrar Javed³, Mark Gorman', Diaa Othman', Muhammad Riaz' \\ ${ }^{I}$ Department of Plastic and Reconstructive Surgery, Castle Hill Hospital, Hull HU16 5JQ, UK. \\ ${ }^{2}$ Department of Ophthalmology, The Johns Hopkins University School of Medicine, Baltimore, MD 21287, USA. \\ ${ }^{3}$ Department of Surgery, The Johns Hopkins University School of Medicine, Baltimore, MD 21287, USA. \\ Correspondence to: Dr. Ammar Asrar Javed, Department of Surgery, Johns Hopkins Hospital, Blalock 618, 600 N. Wolfe Street, Baltimore, MD \\ 21287, USA. E-mail: ajaved1@jhmi.edu
}

How to cite this article: Khan MAA, Aziz K, Javed AA, Gorman M, Othman D, Riaz M. Modified lower eyelid blepharoplasty improves aesthetic outcomes in patients with hypoplastic malar prominences. Plast Aesthet Res 2017;4:228-35.

\author{
Article history: \\ Received: 25 Sep 2017 \\ First Decision: 25 Nov 2017 \\ Revised: 13 Dec 2017 \\ Accepted: 14 Dec 2017 \\ Published: 29 Dec 2017
}

Keywords:

Blepharoplasty,

malar complex,

lower eye lid,

modified blepharoplasty

\begin{abstract}
Aim: Aging affects the appearance of the eyelids and the surrounding malar region. Blepharoplasty improves the aesthetic appearance of this region, and multiple variants of the procedure have been reported. We here report our technique for modified lower lid blepharoplasty and cheek lift for patients with hypoplastic malar regions, which was introduced after observing prominent lower orbital rims in patients with flat malar prominences after blepharoplasty. Methods: This technique combines standard canthopexy and cheek-lift for rejuvenation of the mid-face with redraping of orbital fat and concurrent sub orbicularis oculi fat pad (SOOF) lift to "double-breast" the lower orbital margin. Data on 33 patients who had undergone this modified lower lid blepharoplasty was collected retrospectively. Results: Thirty-three patients underwent the modified lower lid blepharoplasty resulting in smooth and youthful appearance of the malar region that was consistent and sustained. No recurrence of V-deformity was observed on a median follow-up of 14 months. Twenty-two (66.6\%) and 11 $(33.3 \%)$ patients were pleased and satisfied with postoperative outcomes respectively. Three (9.1\%) patients experienced minor postoperative complications and no major complication was observed. Conclusion: The proposed modified lower lid blepharoplasty is a safe and effective alternative to the existing technique with improved aesthetic outcomes and therefore is recommended in patients with flat malar prominences.
\end{abstract}

\section{INTRODUCTION}

Aging is an inevitable natural process of life that affects all parts of the human body. Multiple agerelated changes are observed in the anatomy of the eyelids and the surrounding structures including the malar region. The malar prominence lies just inferior to the eyelid and is an important aesthetic component of the eyelid-check junction. The concomitant loss of the elasticity of the musculature (leading to laxity) and

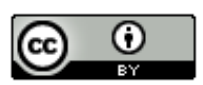

This is an open acess article licensed under the terms of Creative Commons Attribution 4.0 International License (https://creativecommons.org/licenses/by/4.0/), which permits unrestricted use, distribution, and reproduction in any medium, as long as the original author is credited and the new creations are licensed under the identical terms.

For reprints contact: service@oaepublish.com

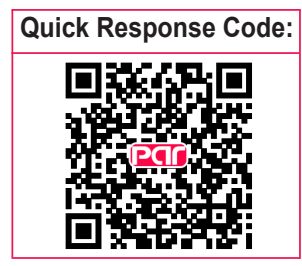


the overlying skin (resulting in a saggy appearance) of the inferior eyelids, contribute significantly to the elongation of the vertical aperture resulting in an increased visibility of the sclera ${ }^{[1-3]}$. Concurrently, pseudo-herniation of the post-septal fat leads to the formation of irregular contours of the lower eyelids. These irregularities along with fat and osseous atrophy lead to the displacement of the eyelid-cheek junction inferiorly and development of the tear trough deformity. Other associated changes include the prominent appearance of the malar bags and skeletonization of the inferior orbital margin ${ }^{[4-7]}$.

Blepharoplasty remains an important modality in lower eyelid rejuvenation leading to a youthful and aesthetically pleasing appearance of the eyes and the malar region. The ideal technique of blepharoplasty still remains debateable, and therefore different variations in the surgical approach have been described ${ }^{[6,8-12]}$. These are aimed at improving aesthetic outcomes and reducing postoperative complications associated with the procedure. Early reports described a sub-ciliary approach which was adopted by Miller ${ }^{[13]}$ to remove excess skin on the eyelids. Successively, a trans-conjunctival approach was described by Bourguet ${ }^{[14]}$ that involved removal of herniated periorbital fat. Traditional blepharoplasty evolved on the basis of these two techniques and involved excision of skin, fat, and muscle with septal plication ${ }^{[6,15]}$. Substantial removal and sculpting of the orbital fat were involved in these techniques, which was aimed at achieving aesthetically acceptable results. However, soon it became evident that this excessive removal resulted in skeletonization of the orbit with resulting hollowed appearance of the eyes ${ }^{[16]}$. This led to further evolution of the techniques by integration of fat preservation. In early 1980's Loeb $^{[17]}$ described a technique that involved sliding of a vascularized fat pad into the cheek, by means of a sub-ciliary approach, to correct the naso-jugal depression (tear trough). Loeb's technique was then further modified by Hamra ${ }^{[18]}$ in 1995 and 2004 ${ }^{[16]}$ and described as the "septal reset" technique; a subciliary technique that was aimed at overcoming the shortcomings of the earlier techniques. Hester et al. ${ }^{[19]}$, later described an approach assisted by an endoscope consisting of subperiosteal dissection of the midface and elevation of the orbicularis muscle based on "passive septal tightening". A transconjunctival technique was then described by Goldberg ${ }^{[20]}$ involving positioning of orbital fat pedicles into a subperiosteal pocket created after incision of the arcus marginalis. Another transconjunctival approach that has been described the repositioning of fat in an intrasuborbicularis oculi fat plane ${ }^{[21]}$.
Table 1: Garcia-McCollough scale for lower eyelid appearance

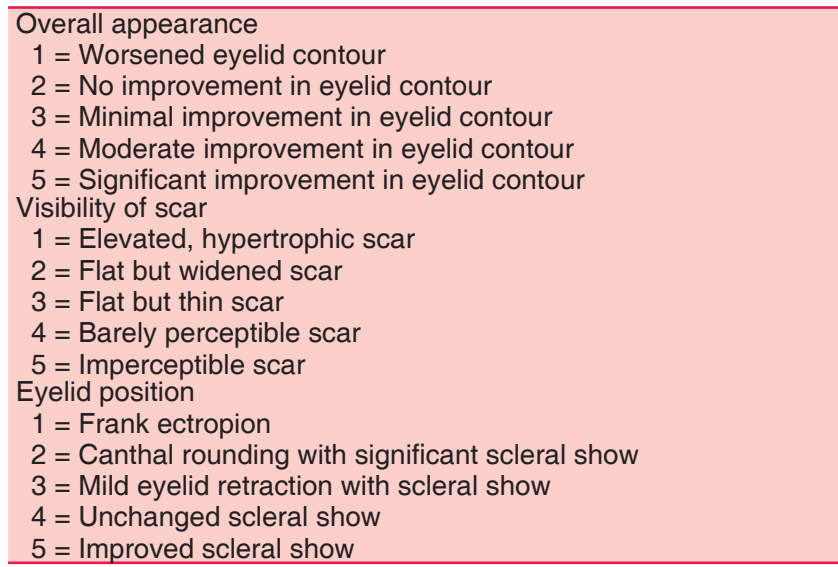

There has always been a room for improvement in the surgical techniques available for lower eyelid rejuvenation ${ }^{[22]}$. Here we present our technique of a modified lower lid blepharoplasty which is a modification of the earlier mentioned techniques tailored to address patients with hypoplastic malar prominences. In our experience, the use of this technique results in improved aesthetic outcomes and is therefore recommended for this select patient population.

\section{METHODS}

\section{Methodology}

Data on all patients who had undergone this modified lower lid blepharoplasty was retrospectively collected from both private and National Health Service records. The aesthetic appearance was assessed using the Garcia-McCollough scale for Lower Eyelid Appearance $[\text { Table } 1]^{[23]}$. Patient satisfaction with the outcomes of the procedure was evaluated using an existing validated questionnaire.

\section{The technique}

The lateral skin incision is marked [Figure $1 \mathrm{~A}]$. It starts 2-3 $\mathrm{mm}$ inferolateral to the lateral canthus and tapers infero-laterally along the natural skin crease for $8-10 \mathrm{~mm}$. Blunt dissection is then employed to make a small subcutaneous pocket under the incision [Figure 1B]. The skin of the lower eyelid is incised horizontally 2-3 mm inferior to the lower lid margin, using tenotomy scissors to prevent any damage to the hair follicles [Figure $1 \mathrm{C}$ ]. The medial margin of the skin incision lies just short of the inferior punctum.

A pre-orbicularis cutaneous flap is then raised to expose the underlying musculature, and the extent of cutaneous undermining depends on the level 

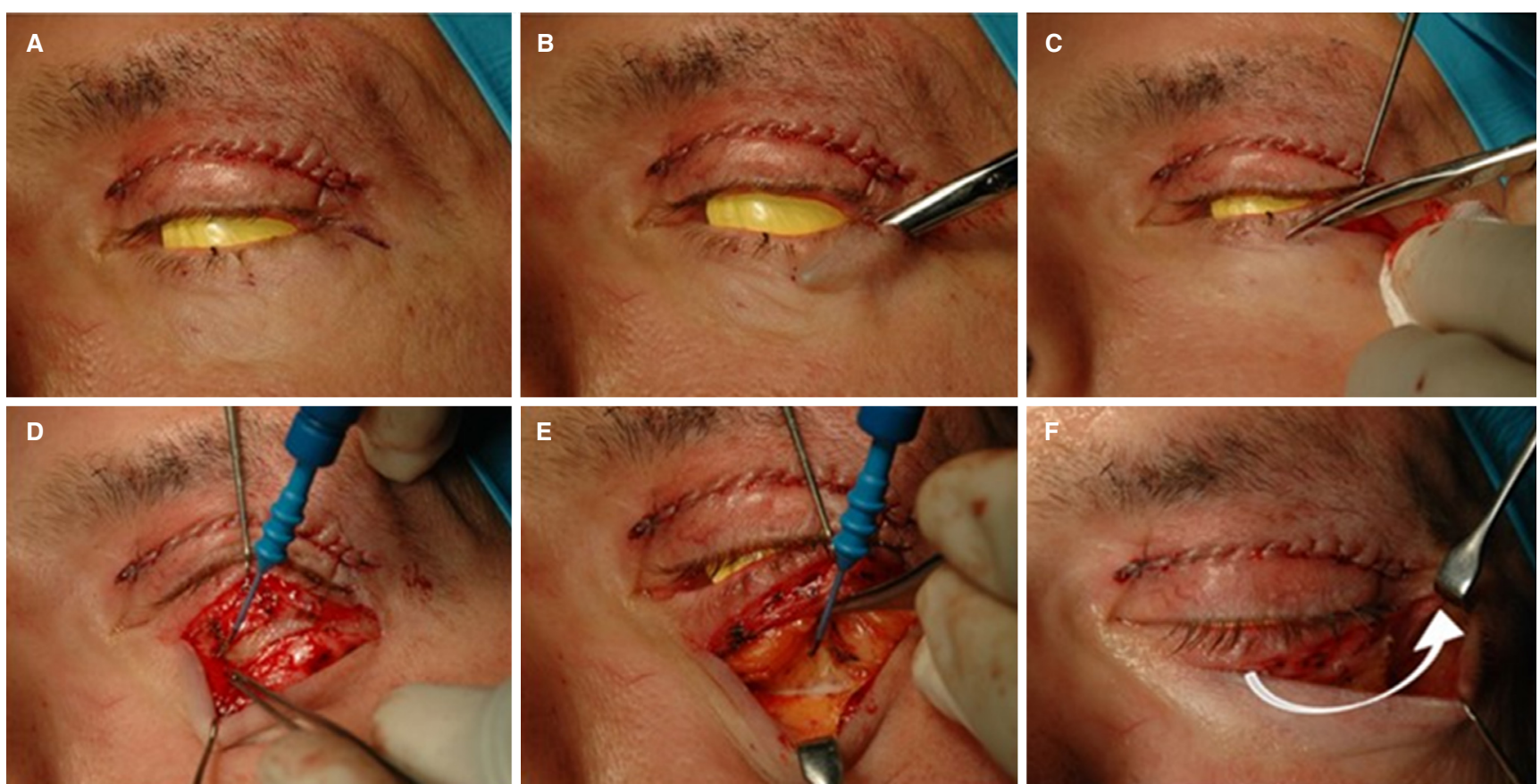

Figure 1: Incision and initial dissection. (A) The lateral skin incision marking; (B) subcutaneous undermining; (C) sub-ciliary incision; (D) incision of the orbicularis oculi muscle; $(E)$ dissection in the sub-muscular plane releasing the fascia over the sub orbicularis oculi fat pad; (F) orbito-malar ligament release and lateral pocket dissection

of skin excision that is clinically required which is generally titrated to each case. A fine tipped cutting diathermy is used to incise the underlying orbicularis oculi muscle preserving $1.5 \mathrm{~cm}$ of the vertical muscle height from the ciliary margin superiorly [Figure 1D]. Further dissection is undertaken infero-laterally in the submuscular plane towards the infraorbital margin and zygoma and the orbito-malar ligament over the sub orbicularis oculi fat pad (SOOF) is released [Figure 1E]. Generous use of cold normal saline is employed after the use of cutting diathermy to cool tissue and reduce the risk of chemosis. The pocket is further extended supero-laterally under the orbicularis oculi till the temporalis fascia to prepare for the lateral canthoplasty and orbicularis suspension sutures [Figure 1F]. No subperiosteal dissection is performed.

The post-septal fat, in its pseudo-herniated state, has an irregular gross appearance. The fat is teased into a uniform apron [Figure 2A] to give it a smooth appearance and is redraped over the inferior orbital margin to augment the volume of this skeletonized anatomical landmark. A $5 / 0$ vicryl suture is used to secure a bite through the septum at $2.5 \mathrm{~cm}$ from the lower lid margin, followed by a bite of the free edge of the post septal fat apron edge and then a bite through the periosteum of the inferior orbital margin and then through the free edge of the post septal fat apron again. Securing this suture simultaneously plicates the septum and secures the re-draped post septal fat to the inferior orbital margin [Figure 2B]. The suture is not cut and a bite of the SOOF is taken, lifting it superiorly and securing it on top of the redraped fat over the inferior orbital margin. This SOOF lifting suture also lifts the malar soft tissue by $2-3 \mathrm{~mm}$, augmenting the volume over the inferior orbital margin and also smoothens the contours of the re-draped post septal fat by "double breasting" it [Figure 2C]. Three-four similar sutures are then used in a medial to lateral manner [Figure 2D] and this two-layered volume augmentation over the skeletonized inferior orbital margin results in an improved aesthetic outcome in patients with hypolastic malar prominences. The excess muscle is then excised using unipolar diathermy [Figure 2E]. The width of this excised muscle depends on its laxity and can vary between 5-12 mm.

This is followed by the placement of a lateral canthopexy suture using a double needled suture (4/0 surgidac-synthetic, non-absorbable). A generous subcutaneous bite of the lateral canthus and adjacent soft tissue is taken and secured to the periosteum that lines the inner surface of the lateral orbital margin at the margin or 2-3 $\mathrm{mm}$ superior to an imaginary line passing through the pupil as dependent on the patient's anatomy [Figure $2 \mathrm{~F}$ ]. This is followed by a cheek/midface lift suture (4/0 surgidac-synthetic, non-absorbable) which includes a bite of the fat pad released from the anterior surface of the zygoma and 

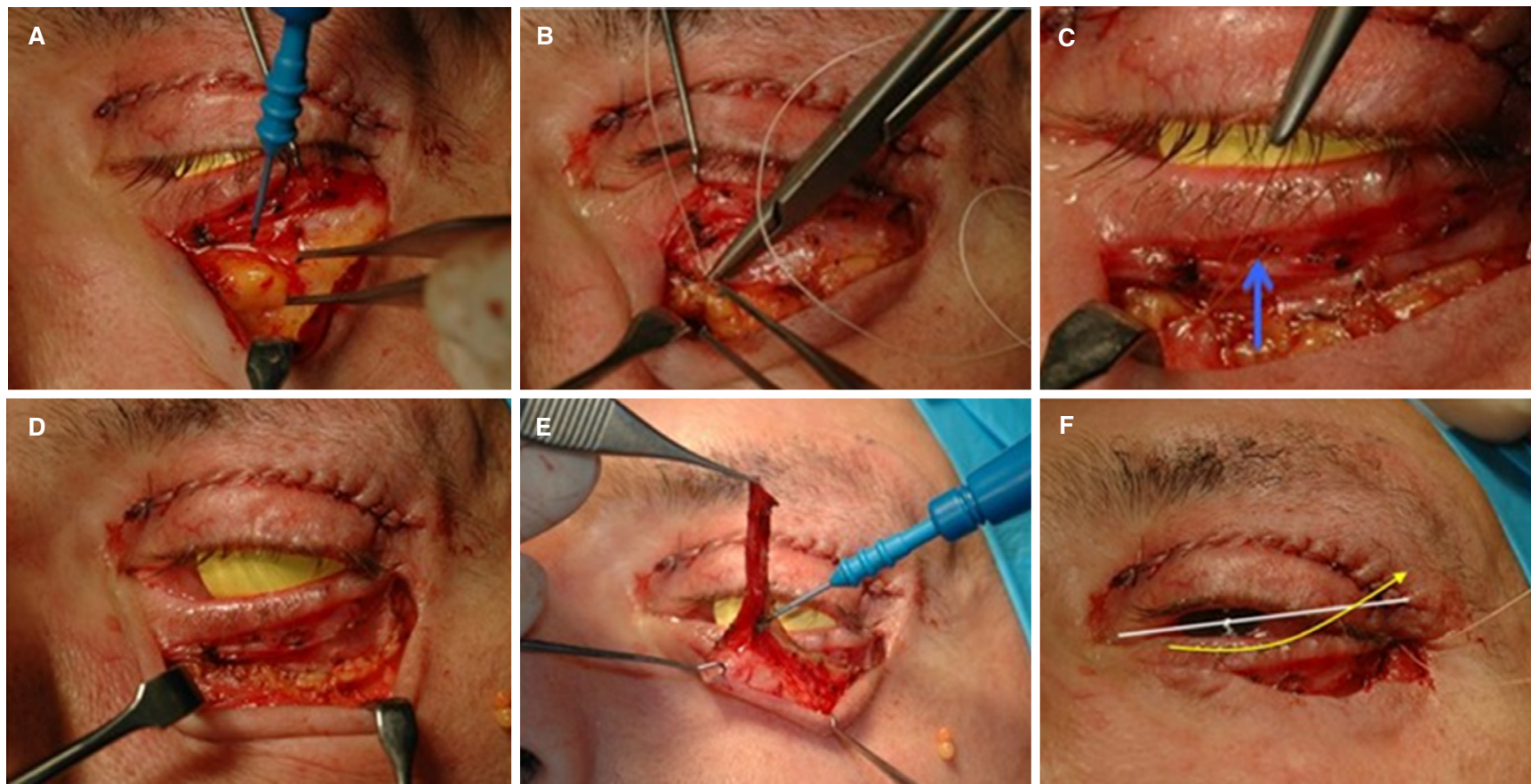

Figure 2: Volume augmentation over the inferior orbital rim and malar tissue lift and lateral canthopexy. (A) The post septal fat in all three compartments is teased into a uniform apron; (B) plication of the inferior orbital septum and redraping of post septal fat over the infraorbital margin (first layer of volume augmentation); (C) sub orbicularis oculi fat pad double-breasting over the post septal fat on the infraorbital margin (second layer of volume augmentation while simultaneously lifting malar tissues) see arrow; (D) three to four similar sutures are used from medial to lateral; $(E)$ excision of excess muscle; $(F)$ lateral canthopexy suture

the under surface of the soft tissue of the cheek in the line of the lateral orbital margin and is secured to a fixed point i.e. the periosteum of the lateral orbital margin. By securing this suture, the bulk of cheek/ midface soft tissue is seen to move upwards and over the inferior orbital margin and zygoma to enhance the fullness of the cheek and provide a youthful appearance.

Later two orbicularis suspension (orbicularis hitch) sutures (4/0 surgidac-synthetic, non-absorbable) are placed that secure the incised inferior edge of the orbicularis occuli muscle to the temporalis fascia above the zygomatic arch [Figure 3A] lateral to the lateral canthus. This further elevates the cheek securing it in this position and eliminating downward pull on the lower eyelid margin. A third orbicularis suspension suture is placed which opposes the superior and inferior incised margins of the orbicularis muscle and secures the complex to the periosteum of the lateral orbital margin [Figure 3B]. The extra lower eyelid skin is excised leaving enough skin to prevent postoperative ectropion [Figure $3 \mathrm{C}$ ].

A lateral contouring suture is then placed using $5 / 0$ prolene, through the skin edges just lateral to the lateral canthus to secure them to the periosteum of the lateral orbital margin. This "quilting" facilitates the creation of a smooth trough which is the natural depression seen lateral to the lateral canthus [Figure 3D]. This suture is left loose and tied at the end of the procedure after placement of the other sutures both medal and lateral to it. The skin of the lateral incision is closed with $6 / 0$ prolene interrupted sutures and the edges are secured medially with 3-4 vicryl rapide $(6 / 0)$ interrupted sutures as shown in the immediately postoperative images [Figure $3 \mathrm{E}$ and F].

Postoperatively the patients are nursed in a head up position with cooling goggles placed above the surgical site.

\section{RESULTS}

We employed the above mentioned technique to perform blepharoplasty in 33 patients between December 2009 and December 2013. The majority of patients $(60.6 \%)$ were female, the mean age was $49.1(39-72)$ years, and the mean BMI was $26.2(19-33) \mathrm{kg} / \mathrm{m}^{2}$.

The mean time taken to perform a unilateral procedure was $23 \mathrm{~min}$ while the mean weight of the excised soft tissue was $12(8-25) \mathrm{g}$. A standard postoperative protocol of an overnight hospital stay was followed for all patients. The mean follow-up time was $14(12.5-19)$ months. The outcomes of interest 

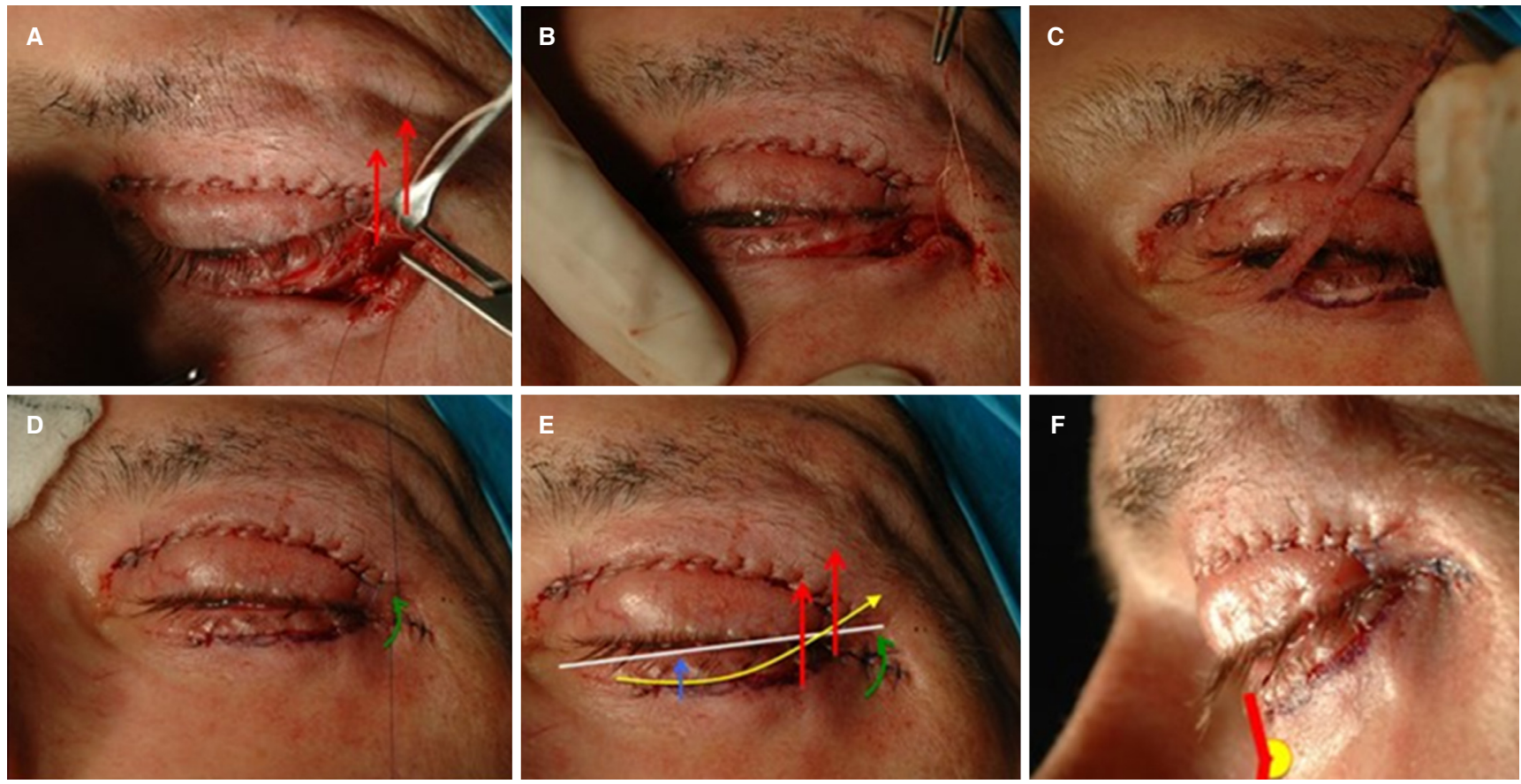

Figure 3: Orbicularis suspension and opposition, reconstruction and immediate postoperative results. (A) Two orbicularis suspension sutures; (B) third orbicularis suture; (C) excess skin excision; (D) lateral contouring suture; (E) immediate postoperative result (anteroposterior view); (F) immediate postoperative result (lateral view)

A

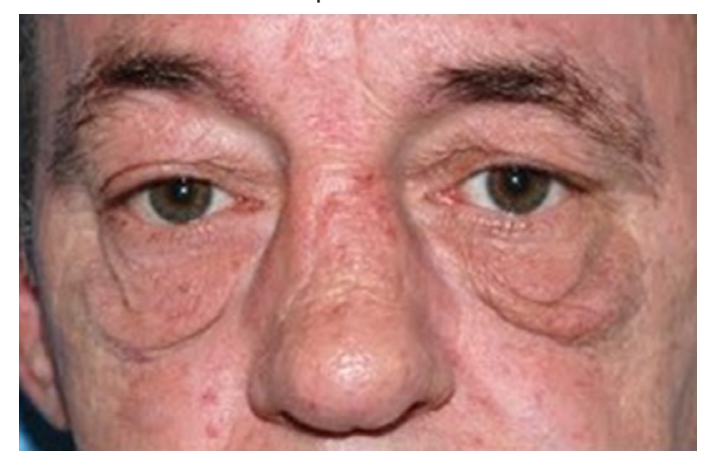

Postoperative

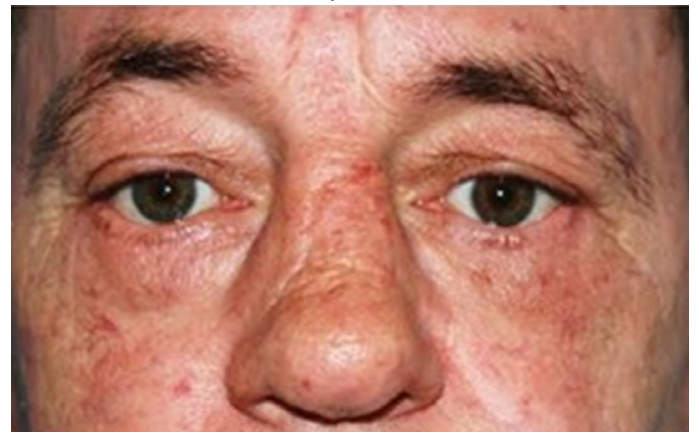

B

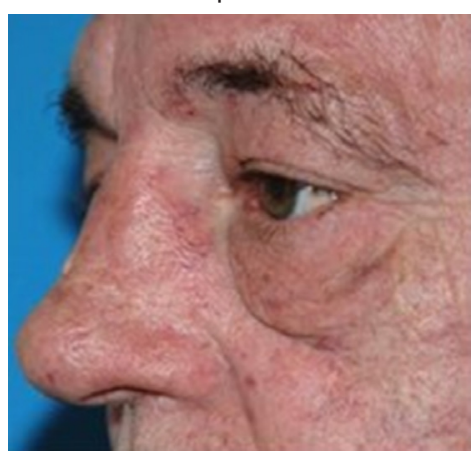

Postoperative

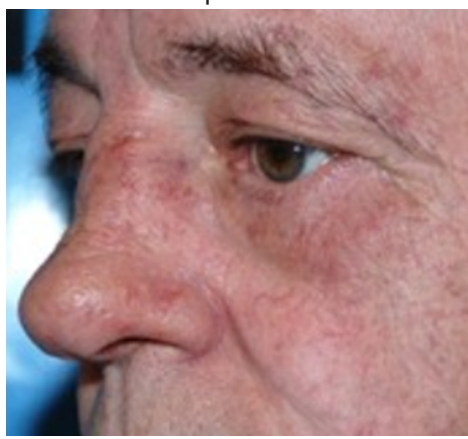

Figure 4: Postoperative outcomes. (A) Pre- and postoperative appearance (antero-posterior view); (B) pre- and postoperative appearance (lateral view)

were the postoperative aesthetic appearance, patient satisfaction, and complications.

The aesthetic appearance was assessed using the Garcia-McCollough scale for Lower Eyelid Appearance. Postoperative photos at long-term follow up (1 year) are shown in Figures 4-7. All patients demonstrated a satisfactory aesthetic appearance. 


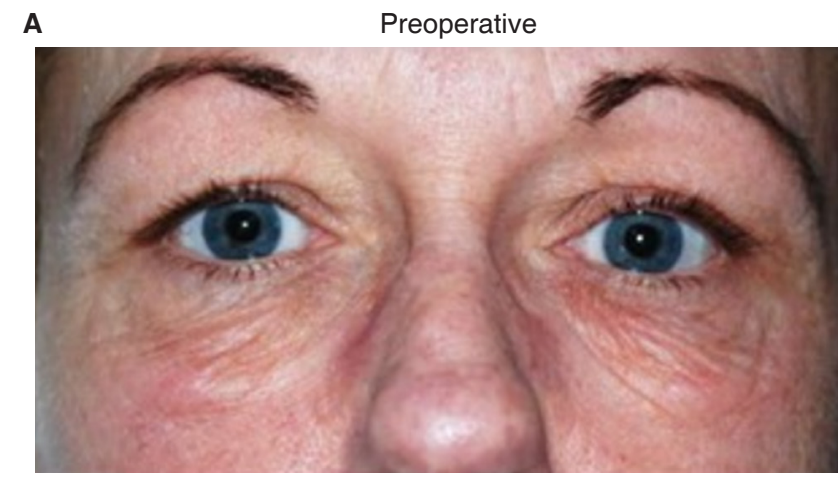

Postoperative

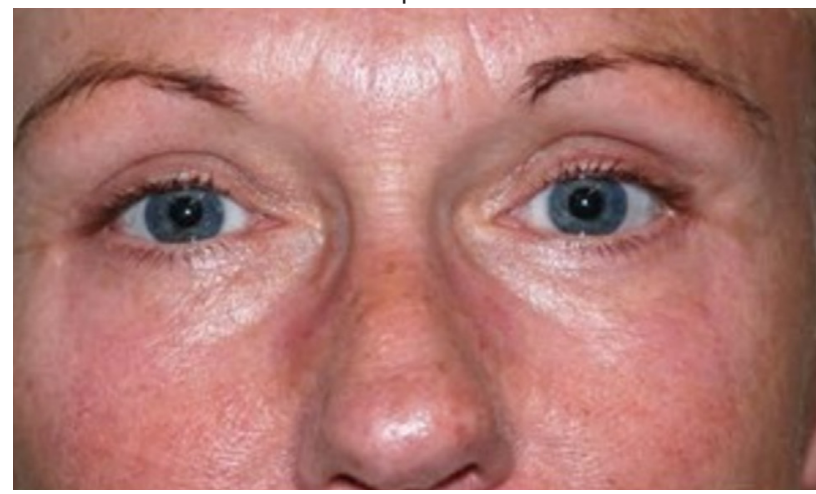

B Preoperative

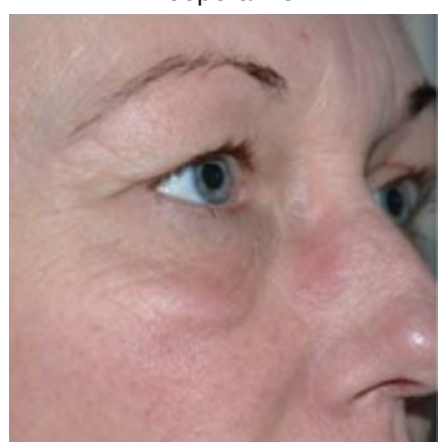

Postoperative

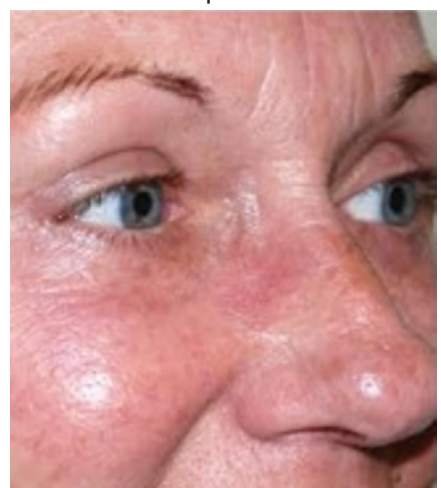

Figure 5: Postoperative outcomes. (A) Pre- and postoperative appearance (antero-posterior view); (B) pre- and postoperative appearance (lateral view)

To assess patient satisfaction a validated satisfaction questionnaire was used. Twenty-two (66.6\%) patients were pleased by the postoperative aesthetic outcome while $11(33.3 \%)$ patients were satisfied. There were no major postoperative complications. Minor complications were observed in $3(9.1 \%)$ patients. These included 1 case each of hypertrophic scarring in the segment of the scar lateral to the lateral canthus, stitch sinus and chemosis. All 3 patients were managed conservatively and showed improvement. No patient developed a postoperative infection, ectropion or scleral show.

\section{DISCUSSION}

Our proposed technique has several features that differentiate it from the traditional blepharoplasty techniques and aims at achieving a better aesthetic outcome in patients with hypoplastic malar eminences.

Firstly, the location of our trans-muscular incision is significantly lower than the cutaneous incision which ensures that both incisions are not at the same level in different planes. This reduces scarring at the same level thus decreasing the chances of development of postoperative ectropion. Our technique is based on fat preservation and the pseudo-herniated post-septal fat pad is used "ecologically" to augment volume over the skeletonized inferior orbital margin. In addition "double breasting" of the SOOF over the stabilized "Iobular" post-septal fat smoothens it, lifts malar tissues and further augments volume over the inferior orbital rim and imparts a fuller appearance to both the infraorbital and malar regions.

Secondly, the placement of the canthopexy sutures raises the lateral canthus superolaterally avoiding a droopy look that is commonly associated with aging. Securing the canthopexy suture to the inner periosteum of the lateral orbital wall allows the lower eyelid to conform better to the contours of the globe. This prevents the formation of an ectropion and ensures proximity of the lower eyelid to the globe to provide protection.

Thirdly, the placement of the two orbicularis suspension (orbicularis hitch) sutures (4/0 surgidacsynthetic, non-absorbable) secure the incised inferior edge of the orbicularis occuli muscle to the temporalis fascia above the zygomatic arch [Figure 2C] lateral to the lateral canthus. This results in a 2-3 mm elevation of the lid-cheek junction further improving the volume deficit in patients with hypoplastic malar prominences. The third orbicularis suspension suture opposes the superior and inferior incised margins of the orbicularis muscle and secures the complex to the periosteum of 
A

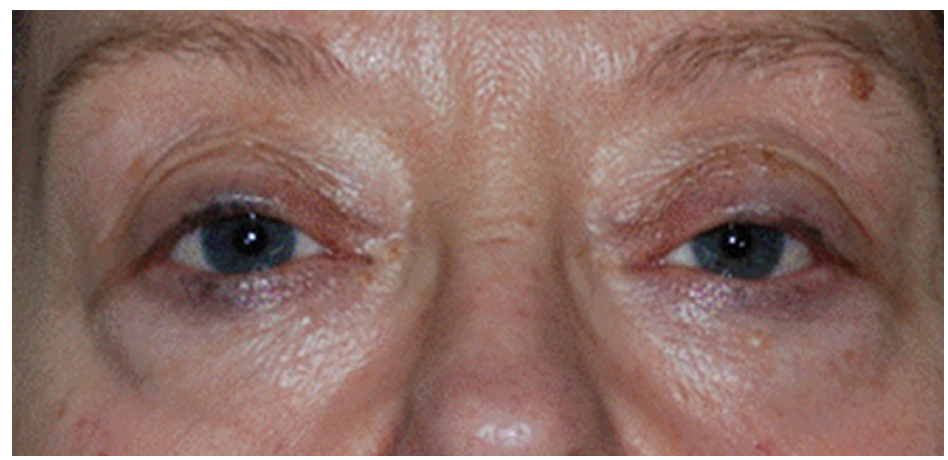

Postoperative

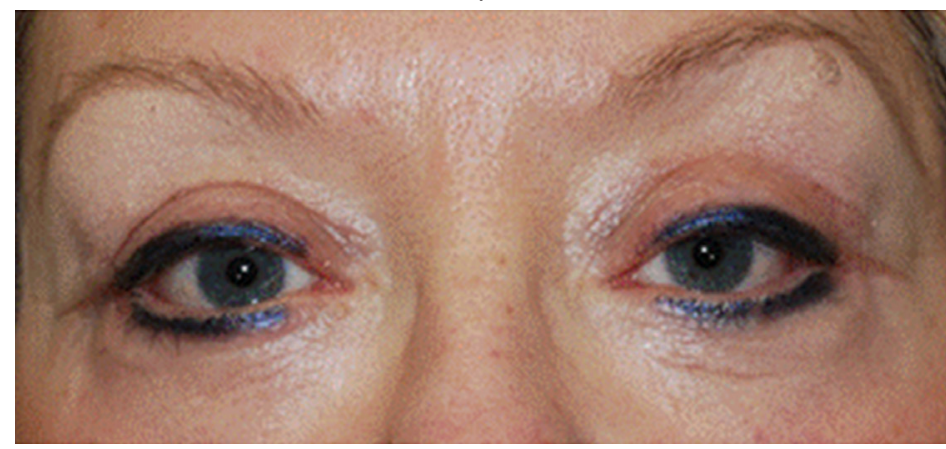

B

Preoperative

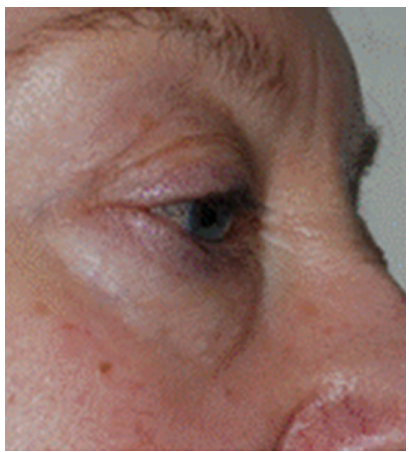

Postoperative

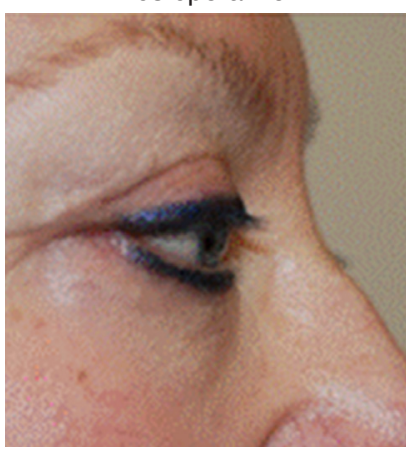

Figure 6: Postoperative outcomes. (A) Pre- and postoperative appearance (antero-posterior view); (B) pre- and postoperative appearance appearance (lateral view)

A

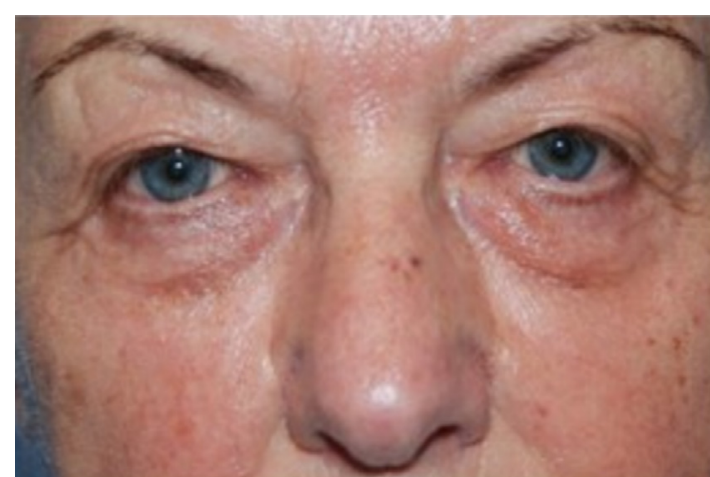

Postoperative

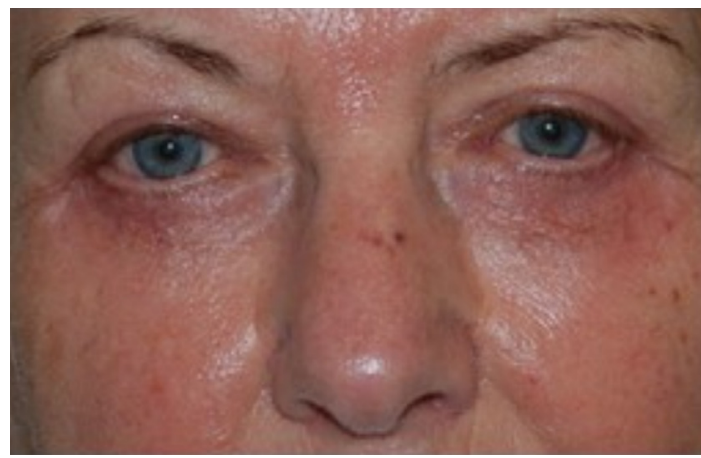

B

Preoperative

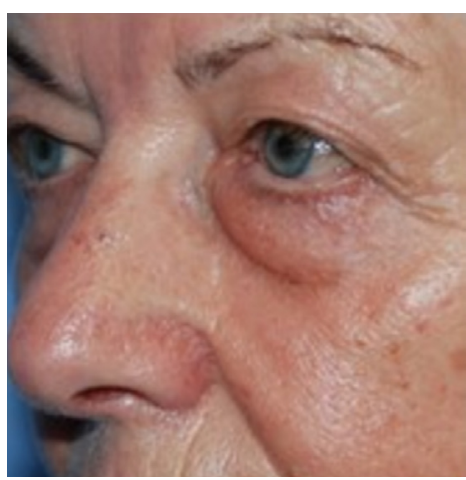

Postoperative

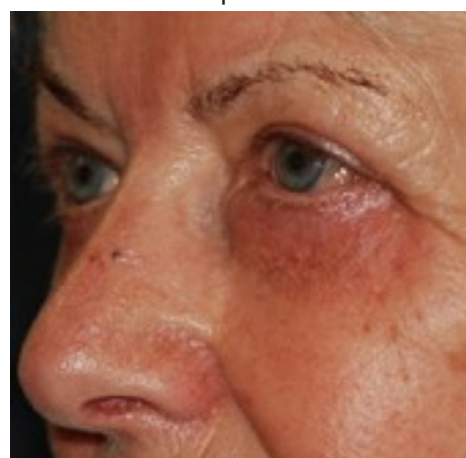

Figure 7: Postoperative outcomes. (A) Pre- and postoperative appearance (antero-posterior view); (B) pre- and postoperative appearance appearance (lateral view) 
the lateral orbital margin. Leaving 1-2 $\mathrm{mm}$ of excess skin while excising the extra lower eyelid skin prevents postoperative ectropion.

The cheek lift and initial two orbicularis suspension sutures raise the malar soft tissues whereas the third orbicularis suture helps avoid overlapping of the muscles and prevents postoperative contour irregularities. The contouring suture lateral to the lateral canthus ensures a smooth trough appearance which is a part of the normal anatomy of the eye thus further enhancing the aesthetic outcomes.

In conclusion, lower eyelid blepharoplasty is a complex procedure and the malar complex must be considered as a part of the lower eyelid when performing this procedure to obtain improved results. Our proposed technique of a modified lower lid blepharoplasty is a safe and effective alternative to the existing technique which improves the aesthetic outcomes.

This technique is valuable in a patient with a flat malar prominence and therefore its use is recommended in the management of this patient cohort.

\section{DECLARATIONS}

\section{Authors' contributions}

Concept and design: M.A.A. Khan, A.A. Javed, M. Gorman, D. Othman, M. Riaz

Data collection and analysis: M.A.A. Khan, K. Aziz, A.A. Javed, D. Othman

Write up: M.A.A. Khan, K. Aziz, A.A. Javed, M. Gorman, D. Othman, M. Riaz

Review and final approval: M.A.A. Khan, K. Aziz, A.A. Javed, M. Gorman, D. Othman, M. Riaz

\section{Financial support and sponsorship} None.

\section{Conflicts of interest}

There are no conflicts of interest.

\section{Patient consent \\ Not applicable.}

\section{Ethics approval Not applicable.}

\section{REFERENCES}

1. Liao SL, Wei YH. Fat repositioning via supraperiosteal dissection with internal fixation for tear trough deformity in an Asian population.
Graefes Arch Clin Exp Ophthalmol 2011;249:1735-41.

2. Innocenti A. Couto RA, Waltzman JT, Drake RL, Zins JE. Evidencebased medicine: a graded approach to lower lid blepharoplasty. Plast Reconstr Surg 2017;140:504e-5e.

3. Chen JL, Liu CH, Yi CG. Indications of transconjunctival orbital septum fat release and preservation for orbitopalpebral sulcus in lower eyelid blepharoplasty. Aesthetic Plast Surg 2017;41:753.

4. Rostami S, de la Torre JI. Blepharoplasty, lower eyelid. Treasure Island (FL): StatPearls Publishing; 2017

5. Bater KL, Ishii M, Nellis JC, Joseph A, Papel ID, Kontis TC, Byrne PJ, Boahene KDO, Ishii LE. A dual approach to understanding facial perception before and after blepharoplasty. JAMA Facial Plast Surg 2017.

6. Chatel H, Hersant B, Bosc R, La Padula S, Meningaud JP. Midface rejuvenation surgery combining preperiosteal midcheek lift, lower blepharoplasty with orbital fat preservation and autologous fat grafting. J Stomatol Oral Maxillofac Surg 2017;118:283-8.

7. Hashem AM, Couto RA, Waltzman JT, Drake RL, Zins JE. Evidencebased medicine: a graded approach to lower lid blepharoplasty. Plast Reconstr Surg 2017;139:139e-50e.

8. Gasgarth RJ, Codner MA. Discussion: extended transconjunctival lower eyelid blepharoplasty with release of the tear trough ligament and fat redistribution. Plast Reconstr Surg 2017;140:283-5.

9. Wong $\mathrm{CH}$, Mendelson B. Extended transconjunctival lower eyelid blepharoplasty with release of the tear trough ligament and fat redistribution. Plast Reconstr Surg 2017;140:273-82.

10. Yi MY, Choi HS, Jang JW, Kim SJ, Jang SY. Asymmetry of preoperative incision design markings for upper blepharoplasty. $J$ Craniofac Surg 2017;28:e419-22.

11. Miranda SG, Codner MA. Micro free orbital fat grafts to the tear trough deformity during lower blepharoplasty. Plast Reconstr Surg 2017;139:1335-43.

12. Mutaf M, Temel M. A new technique for total reconstruction of the lower lid. Ann Plast Surg 2017;78:171-7.

13. Miller CC. Cosmetic surgery: the correction of featural imperfections. Chicago, IL: Oak Printing; 1907.

14. Bourguet J. Fat herniation of the orbit: our surgical treatment bull. Acad Med 1924;92:1270-2.

15. Espinoza GM, Holds JB. Evaluation and treatment of the tear trough deformity in lower blepharoplasty. Semin Plast Surg 2007;21:57-64.

16. Hamra ST. The role of the septal reset in creating a youthful eyelid-cheek complex in facial rejuvenation. Plast Reconstr Surg 2004;113:2124-41; discussion 2142-4.

17. Loeb R. Fat pad sliding and fat grafting for leveling lid depressions Clin Plast Surg 1981;8:757-76.

18. Hamra ST. Arcus marginalis release and orbital fat preservation in midface rejuvenation. Plast Reconstr Surg 1995;96:354-62.

19. Hester TR Jr, Ashinoff RL, McCord CD. Managing postseptal fat in periorbital rejuvenation: anatomic intraorbital replacement using passive septal tightening. Aesthet Surg J 2006;26:717-24.

20. Goldberg RA. Transconjunctival orbital fat repositioning: transposition of orbital fat pedicles into a subperiosteal pocket. Plast Reconstr Surg 2000;105:743-8; discussion 749-51.

21. Mohadjer Y, Holds JB. Cosmetic lower eyelid blepharoplasty with fat repositioning via intra-SOOF dissection: surgical technique and initial outcomes. Ophthal Plast Reconstr Surg 2006;22:409-13.

22. Murri M, Hamill EB, Hauck MJ, Marx DP. An update on lower lid blepharoplasty. Semin Plast Surg 2017;31:46-50.

23. Garcia RE, McCollough EG. Transcutaneous lower eyelid blepharoplasty with fat excision: a shift-resisting paradigm. Arch Facial Plast Surg 2006;8:374-80. 